\title{
Preparation of Silica Nanospheres: Effect of Silicon Alkoxide and Alcohol on Silica Nanospheres
}

\author{
Dong Shin Yun, Hyun Jung Kim, and Jung Whan Yoo* \\ Material Team, Whiteware:Structural Ceramics Center, Korea Institute of Ceramic Engineering \& Technology, \\ Seoul 153-801, Korea. E-mail: jwyoo@kicet.re.kr \\ Received July 29, 2005
}

Key Words : Silica, Nanospheres, Nanoparticle, Silicon alkoxide

Special attention has recently been paid to methods for controlling the nanospheres' size and distribution, because they exhibit peculiar and desirable properties in the wafer polishing process. Monodisperse silica nanospheres were first synthesized by Stober et al. using the sol-gel method, which induces high purity in the resulting particles. ${ }^{1}$ Bogush and Zukoski reported the influence of reaction parameters such as ammonia and water contents on the particles' size and distribution. ${ }^{2}$ They observed that, for a particular concentration of tetraethylorthosilicate (TEOS) with ethanol as solvent, particle size reaches a maximum and then decreases as both ammonia and water concentrations are increased. Similar behavior was observed for all the TEOS concentrations studied, and the maximum particle size moved to higher ammonia and water concentrations as the TEOS concentration was increased. The maximum monodisperse size achievable by this process was found to be 800 $\mathrm{nm}$. While narrow size distributions were achievable by this process, the solid content of the resulting dispersion was less than 2 wt.\%. Attempts to increase solid content by simply increasing the initial TEOS concentration for a particular concentration of ammonia and water resulted in larger particle sizes and broader size distributions.

Recently, silica nanospheres have been considered effective candidates for chemical-mechanical polishing materials, so several investigators have reported ways to control particle size by using reactor type and varying the concentrations of ammonia, water, and alcohol solvent. ${ }^{3-6} \mathrm{Kim}$ et al. found that the effect of the parameters on the particle size of silica nanospheres was increased in the following order: reaction temperature, $\left[\mathrm{H}_{2} \mathrm{O} / \mathrm{TEOS}\right]$ ratio, concentration of ammonia, and feed rate of reactant. ${ }^{3}$ They also examined the influence of reaction method (such as semi-batch reaction and batch reaction) on particle size and distribution. A relatively slow rate of hydrolysis of the TEOS occurred during the semibatch process, which resulted in larger silica particles and a narrower size distribution. ${ }^{4}$

Even though several studies detail how various controlling factors affect the size and distribution of silica nanospheres, there are no systematic reports about the effect of silicon alkoxides and solvent types on nanosphere formation. In this study, we have synthesized silica nanospheres using four different silicon alkoxides (tetramethylorthosilicate (TMOS), tetraethylorthosilicate (TEOS) tetrapropylorthosilicate (TPOS), tetrambutylorthosilicate (TBOS)) and solvents (methanol $(\mathrm{MeOH})$, ethanol (EtOH), propanol ( $\mathrm{PrOH})$, butanol $(\mathrm{BuOH}))$ and characterized the nanospheres' sizes and shapes by FESEM.

This experiment used two types of solutions: a solution " $A$ " of silicon alkoxide in alcohol solvent and a solution " $B$ " of ammonium hydroxide and water in alcohol. "B" was added to " $\mathrm{A}$ " and stirred for $3 \mathrm{~h}$ at room temperature. The resulting powders were obtained by centrifugation and dried at $80{ }^{\circ} \mathrm{C}$ for $12 \mathrm{~h}$. The particle shape and size in this study were determined by a field emission scanning electron microscope (FE-SEM, JEOL JSM-6700F).

Table 1 summarizes the effects of using various silicon alkoxides (TMOS, TEOS, TPOS, and TBOS) on nanosphere shapes and sizes; images are shown in Figure 1. The silica nanoparticles were synthesized using $0.5 \mathrm{M}$ silicon alkoxide, $6 \mathrm{M} \mathrm{H}_{2} \mathrm{O}, 0.7 \mathrm{M} \mathrm{NH}_{4} \mathrm{OH}$, and $10 \mathrm{~mL}$ propanol at room temperature. The particles had round shapes, except those prepared by TMOS, which had irregular shapes and a broad size distribution. TMOS was thus shown to be an inadequate precursor for synthesis of silica nanospheres. Nanoparticles produced by other alkoxides, whose sizes range from 260 $\mathrm{mm}$ to $380 \mathrm{~nm}$, exhibit round shapes and a narrow size distribution. The maximum mean particle size of $380 \mathrm{~nm}$ was observed when using TEOS (Figure 1(b)). As the length of the carbon chain increased from TEOS to TBOS, the particle sizes gradually decreased. This phenomenon might be explained by steric effect of silicon alkoxide on hydrolytic stability. ${ }^{7}$ Aelion et al. reported hydrolysis rate quickly reduced as increasing carbon chain of the silicon alkoxide. ${ }^{8}$

The effects of various alcohols as solvents on silica particle size and distribution are shown in Figure 2. TPOS

Table 1. Effect of silicon alkoxide type on nanosphere size

\begin{tabular}{ccccc}
\hline $\begin{array}{c}\text { Silicon } \\
\text { Alkoxide }\end{array}$ & $\begin{array}{c}\text { Average } \\
\text { Particle Size } \\
(\mathrm{nm})\end{array}$ & $\begin{array}{c}\text { BET surface } \\
\text { area }\left(\mathrm{m}^{2} / \mathrm{g}\right)\end{array}$ & $\begin{array}{c}\text { Pore volume } \\
\left(\mathrm{cm}^{3} / \mathrm{g}\right)\end{array}$ & $\begin{array}{c}\text { SEM } \\
\text { Image }\end{array}$ \\
\hline TMOS & 40 & 283 & 0.70 & Figure 1(a) \\
TEOS & 380 & 93 & 0.38 & Figure 1(b) \\
TPOS & 320 & 11 & 0.22 & Figure 1(c) \\
TBOS & 260 & 11 & 0.16 & Figure 1(d) \\
\hline
\end{tabular}

Reaction conditions; silicon alkoxide $0.5 \mathrm{M}, \mathrm{H}_{2} \mathrm{O} 6 \mathrm{M}, \mathrm{NH}_{4} \mathrm{OH} 0.7 \mathrm{M}$, propanol $10 \mathrm{~mL}$, reaction temperature $25^{\circ} \mathrm{C}$ 


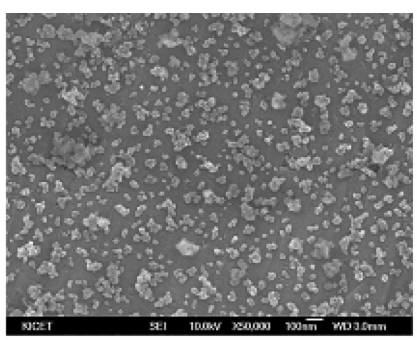

(a)

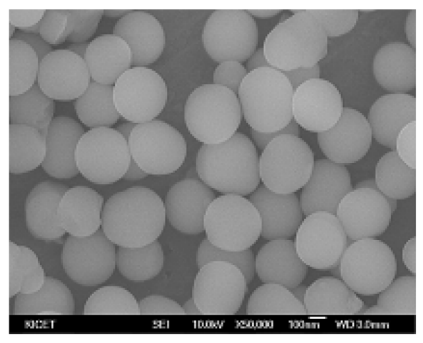

(c)

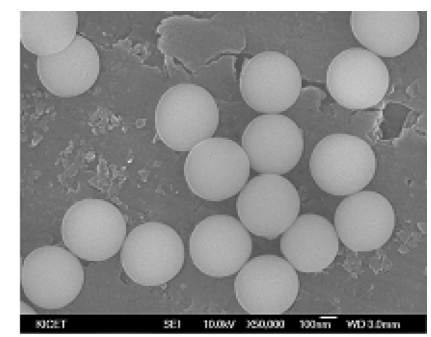

(b)

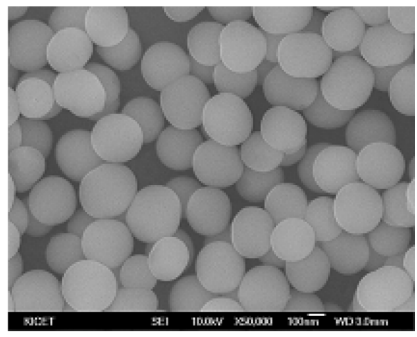

(d)

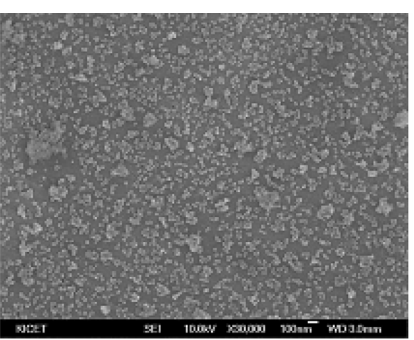

(a)

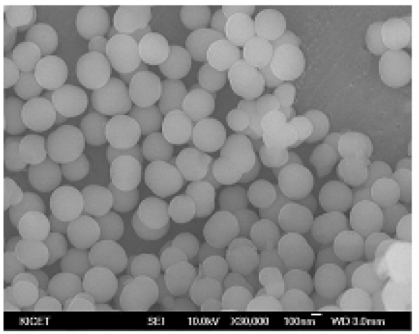

(c)

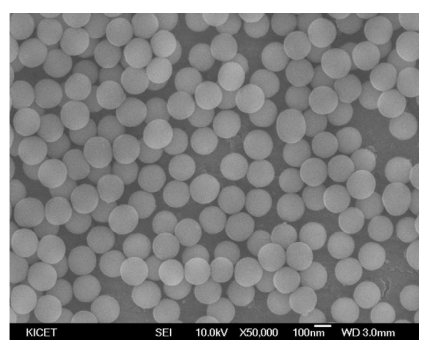

(b)

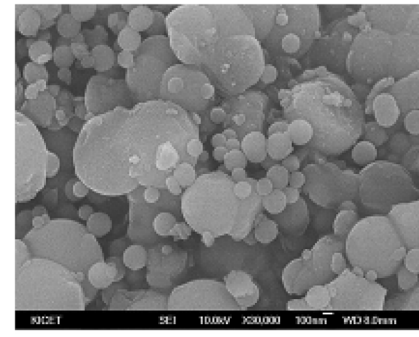

(d)

Figure 1. SEM images of silica nanosphere synthesized with (a) TMOS, (b) TEOS, (c) TPOS and (d) TBOS.

was used as silica precursor and the other parameters were the as those listed in Table 1. As alcohol size increased from $\mathrm{MeOH}$ to $\mathrm{BuOH}$, the average particle size increased from 30 $\mathrm{nm}$ to $800 \mathrm{~nm}$. Generally, the observed particle size distribution was narrow, except for $\mathrm{BuOH}$, whose silica particles were distributed bimodally with peaks at $150 \mathrm{~nm}$ and 800 $\mathrm{nm}$. The alcohol has a function of co-solvent to help mixing silicon alkoxide and water. The used alcohols except $\mathrm{BuOH}$ are well miscible with water, however, $\mathrm{BuOH}$ little soluble so the reaction system using $\mathrm{BuOH}$ is heterogeneous. That is why $\mathrm{BuOH}$ used-reaction shows bimodal distribution. This result agrees well with the findings of Harris et al. ${ }^{9}$ They used different alcohols as solvents and found that the final particle sizes under comparable conditions are smallest in methanol and increased with increasing carbon chain length of the alcohol. The particle size was also found to increase as the alcohol was changed from primary to tertiary. Also, particle size distribution varied from narrow to broad as the alcohol molecular weight was increased. When methanol was used, the particle size is about $30 \mathrm{~nm}$ and the shape is anomalous. Methanol was reported to be effective for making 20-60 nm silica nanoparticles with 1-2 wt.\% solid content, which were prepared by hydrolysis followed by condensation of TEOS. ${ }^{10}$ However, the nanoparticles were not spherically shaped.

In conclusion, we have synthesized diverse silica nanoparticles using various types of silicon alkoxides and alcohols. When different silicon alkoxides were used, the silica particles (except those created using TMOS) were spherical, and, after reaching a maximum, the sizes of the

Figure 2. SEM images of silica nanosphere prepared with (a) $\mathrm{MeOH},($ b) EtOH, (c) $\mathrm{PrOH}$ and (d) $\mathrm{BuOH}$.

particles gradually decreased with increasing carbon chain length. As the alcohol chain length increased from $\mathrm{MeOH}$ to $\mathrm{BuOH}$, the average particle size increased from $30 \mathrm{~nm}$ to $800 \mathrm{~nm}$. In general, all products showed narrow particle size distribution; exceptionally, particles created with $\mathrm{BuOH}$ were distributed bimodally with peaks at $150 \mathrm{~nm}$ and 800 $\mathrm{nm}$. These spherical-shaped particles can be utilized in new materials with high polishing rates and have few defects in chemical-mechanical polishing processes.

Acknowledgements. This work was supported by grant from the Korea Energy Management Corporation.

\section{References}

1. Stober, W.; Fink, A.; Bohn, E. J. Colloid Interface Sci. 1968, 26, 62.

2. Bogush, G. H.; Zukoski, C. F. J. Non-Cryst. Solids 1988, 104, 95.

3. Park, S. K.; Kim, K. D.; Kim, H. T. Colloids Surfaces A: Physicochem. Eng. Aspects 2002, 197, 7.

4. Kim, K. D.; Kim, H. T. J. Sol-Gel Sci. Tech. 2002, 25, 183.

5. Sadasivan, S.; Rasmussen, D. H.; Chen, F. P.; Kannabiran, R. K. Colloids Surfaces A: Physicochem. Eng. Aspects 1998, 132, 45.

6. Kim, K.-S.; Kim, S.-S.; Kim, S.-K.; Kim, J.-K.; Kim, W.-S. Hwahak Konghak 2000, 38, 817.

7. Voronkov, M. G.; Mileshkevich, V. P.; Yuzhelevski, Y. A. The Siloxane Bond; Consultants Bureau: New York, 1978.

8. Aelion, R.; Loebel, A.; Eirich, F. J. Am. Chem. Soc. 1950, 72, 5705.

9. Harris, M. T.; Byers, C. H.; Williams, D. F. Ind. Eng. Chem. Res. 1987, 26, 1916.

10. Sadasivan, S.; Rasmussen, D. H.; Chen, F. P.; Kannabiran, R. K. Colloids Surfaces A: Physicochem. Eng. Aspects 1998, 132, 45. 